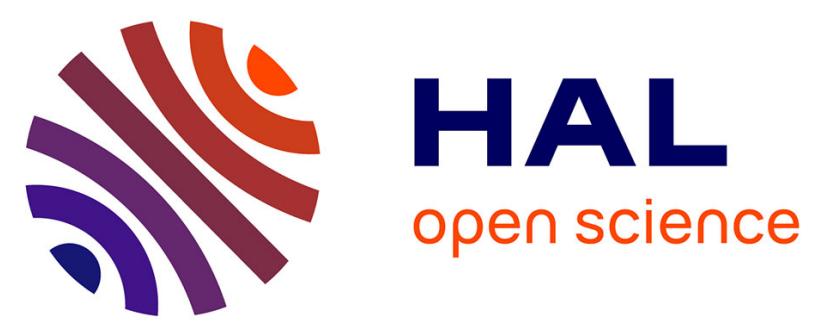

\title{
Hysterectomy, non-malignant gynecological diseases, and the risk of incident hypertension: The E3N prospective cohort
}

\author{
Anne-Laure Madika, Conor James Macdonald, Amandine Gelot, Sixtine \\ Hitier, Claire Mounier-Vehier, Guillaume Beraud, Marina Kvaskoff, \\ Marie-Christine Boutron-Ruault, Fabrice Bonnet
}

\section{To cite this version:}

Anne-Laure Madika, Conor James Macdonald, Amandine Gelot, Sixtine Hitier, Claire Mounier-Vehier, et al.. Hysterectomy, non-malignant gynecological diseases, and the risk of incident hypertension: The E3N prospective cohort. Maturitas, 2021, 150, pp.22-29. 10.1016/j.maturitas.2021.06.001 . hal03336373

\section{HAL Id: hal-03336373 \\ https://hal.science/hal-03336373}

Submitted on 8 Sep 2021

HAL is a multi-disciplinary open access archive for the deposit and dissemination of scientific research documents, whether they are published or not. The documents may come from teaching and research institutions in France or abroad, or from public or private research centers.
L'archive ouverte pluridisciplinaire HAL, est destinée au dépôt et à la diffusion de documents scientifiques de niveau recherche, publiés ou non, émanant des établissements d'enseignement et de recherche français ou étrangers, des laboratoires publics ou privés. 


\section{Highlights}

- In this study, hysterectomy, with or without oophorectomy, was associated with an increased risk of hypertension.

- Endometriosis was associated with an increased risk of hypertension.

- A history of uterine fibroids was associated with an increased risk of hypertension.

- Associations between hypertension and non-malignant gynecological diseases were independent of a history of hysterectomy. 
Hysterectomy, non-malignant gynecological diseases, and the risk of incident hypertension: The E3N prospective cohort

Anne-Laure Madika ${ }^{\mathbf{a}, \mathbf{b}}$, Conor James MacDonald ${ }^{\mathbf{c}, \mathbf{d}}$, Amandine Gelot ${ }^{\mathbf{c}}$, Sixtine Hitier ${ }^{\mathbf{e}}$, Claire MounierVehier $^{\mathbf{a}, \mathbf{b}}$, Guillaume Béraud ${ }^{\mathbf{b}, \mathbf{f},}$, Marina Kvaskoff $\mathrm{f}^{\mathbf{c}, \mathbf{d}}$, Marie-Christine Boutron-Ruault ${ }^{\mathbf{c}, \mathbf{d}}$, Fabrice Bonnet $^{\mathrm{e}}$

${ }^{a}$ CHU Lille, Institut Cœur-Poumon, Médecine Vasculaire et HTA, F-59000 Lille, France

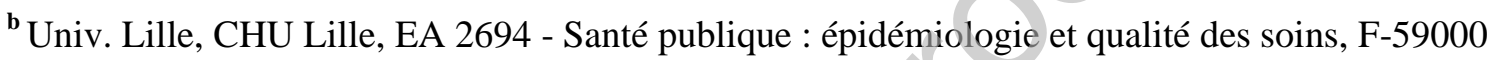
Lille, France

${ }^{\mathbf{c}}$ INSERM U1018, Center for Research in Epidemiology and Population Health (CESP), Institut Gustave Roussy, Villejuif, France.

${ }^{\mathrm{d}}$ Université Paris-Saclay, Université Paris-Sud, Villejuif, France.

${ }^{\text {e }}$ CHU Rennes, Université de Rennes 1-Rennes, France.

${ }^{\text {f }}$ CHU Poitiers, Université de Poitiers, Poitiers, France.

Corresponding author: Marie-Christine Boutron-Ruault. Université Paris-Saclay, Université ParisSud, Villejuif, France. Email: marie-christine.boutron@gustaveroussy.fr. 


\section{ABSTRACT}

\section{Objectives}

While it has been reported that women with uterine fibroids or endometriosis are commonly overweight and hypertensive, the association between non-malignant gynecological diseases and the risk of hypertension has been little studied prospectively. The aim of this study was to investigate in a large French cohort of women whether a history of hysterectomy, uterine fibroids, or endometriosis was prospectively related to an increased risk of incident hypertension.

Study design

We analyzed 50,286 women from the E3N cohort who were free of hypertension at baseline, with a median follow-up of 16.4 years.

Main outcome measures

Gynecological diseases were based on self-report. Cox proportional hazards models with age as the timescale were used to estimate hazard ratios (HRs) and 95\% confidence intervals (CIs). Covariates included smoking status, body mass index (BMI), physical activity, and hormonal factors.

Results

A total of 12,073 women (24\%) developed hypertension during follow-up. Women with a history of hysterectomy had an increased risk of incident hypertension, which persisted after adjustment for potential confounding factors (adjusted $\mathrm{HR}=1.18,95 \%$ CI 1.12-1.24). Risk was similar in women with hysterectomy with or without oophorectomy. Risk of hypertension was higher in women with a history of endometriosis $\left(\mathrm{HR}_{\text {endometriosis }} 1.19,95 \% \mathrm{CI} 1.11-1.22\right)$ or uterine fibroids $\left(\mathrm{HR}_{\text {fibroids }} 1.18\right.$, 95\% CI 1.13-1.22), irrespective of hysterectomy. Associations were similar after further adjustment for BMI.

Conclusions 
Hysterectomy and non-malignant gynecological diseases were associated with an increased risk of hypertension in this large prospective study. Women with these conditions may benefit from blood pressure monitoring.

ClinicalTrials.gov identifier: NCT03285230

Keywords: endometriosis, uterine fibroids, hypertension, hysterectomy, epidemiology

\section{Introduction}

Hypertension is the main risk factor for cardiovascular diseases (CVD), which are the primary cause of death in women [1]. Recent epidemiological studies have shown that the proportion of deaths attributable to CVD is higher in women (49\%) than in men (40\%) [1]. An increase in the incidence of CVD has been observed in younger women (under 60 years old) due to the modernization of lifestyle over the past decades $[1,2]$. Better knowledge is therefore needed to fill the gender gap and improve cardiovascular health in women [3].

Hypertension affects $26 \%$ of the world population with a steady increase in prevalence [4,5]. It is often silent, underdiagnosed, and undertreated, especially in women [5, 6]. Hypertension is more frequent in women after menopause than in men [4] and has a more deleterious impact on the risk of cardiovascular events in women as compared to men [7, 8]. Identification of risk factors for hypertension is therefore crucial to early diagnose and manage hypertension in order to prevent its cardiovascular complications [3]. Several female-specific risk factors for hypertension have been identified, including preeclampsia and use of oral contraceptives [3]. Other factors such as hysterectomy or non-malignant gynecological disease could also be associated with the risk of hypertension but results from previous studies are unclear [9-15]. 
Hysterectomy is one of the most common gynecological procedures and is most often performed in case of non-malignant diseases such as fibroma or endometriosis $[16,17]$. Women undergoing this surgery may experience metabolic changes by losing the protective effect of estrogens on cardiovascular health $[18,19]$. An association between hysterectomy, with or without oophorectomy, and hypertension and cardiovascular risk has been reported in previous studies [9-12], but results are inconsistent. Risk of hypertension was increased after hysterectomy in some studies $[9,11,12]$ but not in all studies [10]. Most of these studies were based on small population without prospective follow-up and did not analyze major potential confounding such as body mass index (BMI), often increased in women with hysterectomy [11], and use of hormone replacement therapy (HRT).

Similarly, associations between non-malignant gynecological conditions, such as endometriosis and fibroids, and the risk of hypertension are unclear, and the confounding or mediating effects by other risk factors or by hysterectomy, frequent treatment of these diseases, are still unknown [11, 13-15, 2023]. Additional large cohort studies are warranted to confirm the association between these conditions and the risk of incident hypertension.

This study aimed to prospectively assess the association between hysterectomy, non-malignant gynecological diseases (uterine fibroids and endometriosis), and the risk of incident hypertension in a large prospective cohort of French women.

\section{Materials and Methods}

\subsection{The E3N cohort}

The E3N study (Etude Epidémiologique de Femmes de la Mutuelle Générale de l'Education Nationale) is a French prospective cohort started in 1990. The study included 98,995 women aged 4065 years at baseline and insured by a health insurance plan for workers in the National Education System and their families [24]. Participants have completed self-administered questionnaires with a mean response rate of $83 \%$ and total loss to follow-up since 1990 of less than 3\%. Questionnaires were completed every 2 to 3 years $(1990,1992,1993,1995,1997,2000,2002,2005$, and 2008). A 
drug reimbursement claims database has also been available since 2004. All women provided written informed consent and the study was approved by the French National Commission for Data Protection and Individual Freedom.

\subsection{Population for analysis and follow-up}

Follow-up started at the date of return of the second questionnaire (1992) from which first information on hysterectomy and non-malignant gynecological diseases was obtained. Participants contributed person-years of follow-up until the date of diagnosis of hypertension, the date of the last completed questionnaire, or the date at which the last E3N questionnaire used for this study was sent to participants (June 25, 2008), whichever occurred first.

Among the 98,995 women from the cohort, we excluded those with no response to the second questionnaire and no information on gynecological history $(n=12,831)$, no follow-up data ( $n=1852)$, prevalent hypertension at baseline $(n=31,177)$, prevalent cancer at baseline $(n=2796)$, or missing information on age at hysterectomy $(n=53)$, resulting in an analysis sample of 50,286 women.

\subsection{Hypertension assessment}

Participants were asked to report in each questionnaire the presence of hypertension, date of diagnosis, and the use of antihypertensive treatment. The month and year of diagnosis were provided in most cases (69\%). For individuals for whom the month of diagnosis was missing (14\% of cases), it was imputed to June of the year of diagnosis. For cases with no year of diagnosis (17\%), the diagnosis date of hypertension was set at the middle of the questionnaire cycle during which incident hypertension was first reported. Most cohort participants (98\%) were active members of the health insurance plan, which provided us with a drug-reimbursement database starting in January 2004. For cases identified after 2004, we used either the self-reported date of diagnosis or the first date of drug reimbursement for antihypertensive medications [diuretics, beta-blockers, calcium antagonists, and angiotensin-converting enzyme inhibitors (Anatomical Therapeutic Chemical Classification System codes $\mathrm{C} 02, \mathrm{C} 03, \mathrm{C} 07, \mathrm{C} 08$, and $\mathrm{C} 09$, respectively)] regardless of the first date of diagnosis. 
We assessed the validity of self-reported hypertension in the E3N cohort using information on the health insurance plan drug-claims database. In women who were alive in January 2004 and up to their response to the last questionnaire in 2008 , we observed a positive predictive value of $82 \%$ of selfreported hypertension compared with self-report to a drug reimbursement corresponding to any of the previously specified codes.

\subsection{Assessment of hysterectomy and benign gynecological diseases}

Starting from the 1992 questionnaire, hysterectomy and oophorectomy status (none, or uni- or bilateral), and age at surgery were self-reported in each follow-up questionnaire. Endometriosis and uterine fibroids were self-reported in each questionnaire as for surgical treatments for these diseases. For all diseases, additional information on diagnostic procedures such as laparoscopy, biopsy, hysterography, hysteroscopy, or ultrasonography were recorded in the second (1992), third (1993) and forth (1994) questionnaires. For each gynecological disease, we considered separately those treated by surgery or laparoscopy, those with at least one treatment or non-surgical diagnostic procedure, and self-reported diseases without confirmation of surgery. Moreover, a validation study of endometriosis cases was performed by sending a specific questionnaire to 200 randomly selected women who selfreported surgical treatment or diagnosis of endometriosis and hospitalization reports. Among the 183 women who replied (92\%), $75 \%$ (137 of 183) were confirmed, and the date of diagnosis was correctly reported in $82 \%$ of the validated cases (112 of 137) [25].

\subsection{Assessment of covariates}

Information on age at menarche, physical activity (metabolic equivalent of tasks [METs]-hr/week), use of intrauterine devices, and number of pregnancies was based on self-reports from the baseline questionnaire. Use of oral contraceptives, menopausal hormone therapy (MHT), and smoking status were updated at each questionnaire and considered in the analyses as time-dependent variables. For diabetes, we used self-reports, supplementary questionnaires, and the drug-reimbursement database [26]. Self-reported height and weight were used to calculate body mass index (BMI) in $\mathrm{kg} / \mathrm{m}^{2}$. In the cohort, self-reported anthropometry has proven reliable in a validation study [27]. Habitual intakes of 
alcohol and mean daily consumption of fruit and vegetables were estimated from the 1993 dietary questionnaire, as previously described [28]. Menopausal status and age at menopause were determined from regularly updated information on menstrual periods, MHT use, self-reported menopausal status, and menopausal symptoms, as detailed elsewhere [29].

\subsection{Statistical analyses}

Baseline characteristics of the study population were described according to medical history of hysterectomy and gynecological diseases. Cox proportional hazards regression models with age as the timescale were used to estimate Hazard Ratios (HRs) and 95\% Confidence Intervals (CIs) of incident hypertension associated with a history of hysterectomy or gynecological disease. Women diagnosed with cancer up to 18 months after hysterectomy were censored at the date of cancer diagnosis in order to consider only non-malignant indications of hysterectomy.

When studying gynecological diseases (medically or surgically confirmed), women who only reported diagnosis but did not provide information on diagnostic procedure or surgical treatments were censored at the report of clinical diagnosis in order to consider only women who detailed information on non-malignant gynecological diseases. Hysterectomy status and non-malignant gynecological disease were analyzed as time-dependent variables. When the variables were not available at a given questionnaire, the preceding value was considered until the next known value. The proportional hazards hypothesis was verified for all time-independent variables of interest using log-log survivor plots. Models were univariable and then further adjusted for a list of established hypertension risk factors or variables leading to potential confounding (detailed in Tables 2 and 3).

Potential interaction between hysterectomy, and previous history of endometriosis or fibroids was considered by including the cross term between the variables in the model. The risk of hypertension was then assessed by considering: no hysterectomy and no history of endometriosis (as reference), hysterectomy and no history of endometriosis, and finally hysterectomy and history of endometriosis. Fibroids history was considered similarly. 
BMI was evaluated as a potential effect modifier by adding an interaction term in the final model and testing its statistical significance. Additional analysis was performed by considering age at hysterectomy and involved ranking the hysterectomy variable as: no hysterectomy, hysterectomy < age 40 , age $40<=$ hysterectomy < age 50, hysterectomy >= age 50. Sensitivity analysis with further adjustment for alcohol consumption and fruit and vegetable intake was performed in 40,721 women free of hypertension who responded to the 1993 dietary questionnaire.

Robustness to unmeasured confounding in the multivariable Cox regression model for analysis of association between hysterectomy, history of endometriosis or fibroids and the risk of hypertension was quantified by an E value for effect estimate and 95\% CI [30].

All tests were two-sided, and statistical significance (P-value) was set at the 0.05 level. All analyses were performed using the Statistical Analysis Systems (SAS) software, version 9.4 (SAS Institute, Inc, Cary, North Carolina).

\section{Results}

Mean age of women at the beginning of follow-up was $50.0 \pm 6.2$ years. Among 50,286 women considered in the study, 12,073 cases of hypertension were diagnosed during 669,947 person-years (PY) of observation (median follow-up duration of 8.8 [4.3-12] years for cases and 16.3 [14.9-16.4] years for non-cases) at a rate of 18.0 cases per 1000 PY. Mean age at the diagnosis of hypertension was $59.5+/-7.9$ years. As shown in Table 1 , women with a history of hysterectomy were more likely to have a younger age at menopause and to use MHT as compared with those without hysterectomy. The same was found in women with a history of fibroids or endometriosis as compared with those without these conditions (supplementary Table 1 and 2).

\subsection{Hysterectomy, oophorectomy, and risk of hypertension}

During the study period, 8511 women reported having a hysterectomy (including 5042 women at baseline), at a mean age of $48.3 \pm 8.2$ years. Women with a history of hysterectomy had an increased risk of incident hypertension ( $\mathrm{HR}=1.18,95 \% \mathrm{CI} 1.12-1.24)$, as compared with women without 
hysterectomy after adjustment for smoking, physical activity, diabetes, and reproductive factors including use of hormonal treatments and age at menopause (Table 2). Associations were similar although slightly attenuated after additional adjustment for BMI $(\mathrm{HR}=1.13,95 \% \mathrm{CI} 1.08-1.19)$. The absolute risk of hypertension was 20 per 1000 person-years in women with hysterectomy versus 17 per 1000 person years in women without hysterectomy.

The risk of hypertension increased with decreasing age at hysterectomy $(\mathrm{HR}=1.28,95 \% \mathrm{CI} 1.13-1.45$ under 40 years and $\mathrm{HR}=1.12,95 \% \mathrm{CI} 1.03-1.22$ over 50 years, $\mathrm{p}$ trend $<0.001$ ). When considering types of surgery, risks were similar in women with hysterectomy with or without oophorectomy, and whether the latter was uni- or bilateral (supplementary Table 3). There was no association between oophorectomy alone and risk of hypertension (Table 2). Further adjustment for dietary components did not change the results (data not shown). The association between a history of hysterectomy or oophorectomy and incident hypertension was not modified by BMI ( $\mathrm{p}$ interaction $=0.90$ and 0.38 , respectively) and was observed in all corresponding strata.

\subsection{Non-malignant gynecological diseases and hypertension}

During the study period, 3581 women reported endometriosis, and 14,866 uterine fibroids. The risk of hypertension increased in case of history of endometriosis (HR 1.19, 95\%CI 1.11-1.22) or uterine fibroids (HR 1.18, 95\%CI 1.13-1.22) (Table 3), and associations were similar for all modes of diagnosis.

No interaction was found between hysterectomy, and previous history of endometriosis or fibroids. Compared to women with no hysterectomy or history of non-malignant gynecological diseases, the highest risk was for women with both hysterectomy and either history of endometriosis or fibroids (adjusted HR 1.24, 95\%CI 1.11-1.38 and 1.18, 95\%CI 1.12-1.25, respectively, Table 4). Further adjustment for dietary intake did not change the results (data not shown). 
The association between a history of endometriosis or fibroids and incident hypertension was not modified by BMI ( $\mathrm{p}$ interaction $=0.92$ and 0.87 , respectively) and was consistent in all corresponding strata.

The approximate $\mathrm{E}$ value for unmeasured confounding for the point estimate and for the lower limit of 95\% CI for analysis of association between hysterectomy, history of endometriosis or fibroids and the risk of hypertension are presented in supplementary Table 4.

\section{Discussion}

In this large prospective cohort study, we found a positive association between a history of hysterectomy, with or without oophorectomy, and risk of incident hypertension, after adjustment for body mass index, diabetes, smoking status, physical activity and hormonal and reproductive factors including use of MHT and age at menopause. We also observed an association between a history of fibroid or endometriosis and the risk of hypertension, including in the absence of hysterectomy.

\subsection{Hysterectomy}

Previous studies of the link between hysterectomy and the subsequent risk of hypertension are inconsistent. A positive association was found in some studies $[9,12,31]$ but not all $[10,11]$. It is still unclear whether the increased risks of hypertension and CVD is due to the effects of hysterectomy or to the effects of baseline adverse characteristics of treated women [32]. Obesity was notably described as a likely explanation of the association between hysterectomy and hypertension, as women who undergo hysterectomy are more likely to be obese or have pre-existing risk factors $[11,33]$. However, in most studies, detailed BMI or lifestyle factors were not assessed while it was the case in our study. In this study, adjustment for diabetes, BMI and lifestyle factors only attenuated the association between hysterectomy and hypertension suggesting an independent association.

When considering type of gynecological surgery, we found that hysterectomy with or without oophorectomy was associated with hypertension risk. Oophorectomy in case of hysterectomy did not provide additional risk and oophorectomy alone was not associated with increased risk of hypertension. Some studies have reported that hysterectomy even without oophorectomy was 
associated with an increased risk of hypertension and CVD in women [31, 34], notably in younger ones. Bilateral oophorectomy was also found in several studies to be associated with increased risks of CVD and mortality in women below 50 [35-37]. However, this increased risk was found in women who had never used estrogen therapy but not in treated women $[35,37]$. This may explain why oophorectomy was not associated with an increased risk of hypertension in our study, since analyses were adjusted for the use of MHT. Moreover, the association of hypertension with bilateral oophorectomy is mainly seen in younger ages (38) and in our cohort, early menopause percentages were relatively low. This may offer a possible explanation on the absence of an association in our study.

The mechanisms involved in the association between hysterectomy and hypertension and cardiovascular risk remain unclear. One of the main hypotheses is that hysterectomy may cause premature ovarian failure and subsequent hormonal effects due to oophorectomy, or disruption of ovarian circulation in case of hysterectomy alone $[9,31]$. This explanation is supported by the fact that the risk is found to be higher in younger women and in women with no hormonal treatment. The association between hysterectomy and hypertension could also be partly due to the indication itself of hysterectomy. As discussed further, different mechanisms could explain association between nonmalignant gynecological diseases and hypertension.

\subsection{Non-malignant gynecological diseases}

Women who reported having been diagnosed with endometriosis or fibroids had an increased risk of hypertension after adjustment for multiple risk factors, including menopausal hormonal treatment. Only one previous prospective study has assessed the association between endometriosis and hypertension [13]. In this large cohort study involving 116,430 nurses, women with laparoscopicallyconfirmed endometriosis had an increased risk of hypercholesterolemia and hypertension compared with women without endometriosis (adjusted HR 1.14, 95\%CI 1.09-1.18). In another study performed on the same sample, endometriosis was linked to a higher risk of coronary heart disease (CHD) [39]. 
A small number of studies have evaluated the association between fibroids and hypertension with conflicting results. Some studies have reported that a history of fibroids was associated with hypertension and atherosclerosis, in line with our results $[14,15,23]$. In a Dutch cross-sectional study, women with surgically-treated fibroids had a higher hypertension prevalence compared with controls, independently from age and BMI [14]. In another study, the same investigators found that these women had more asymptomatic organ damage due to hypertension, particularly among young women [15]. In a cohort of 972 women aged 35-49, presence of fibroids was found to be associated with most cardiovascular risk factors including hypertension, but not with subclinical CVD [40]. Finally, in another study, investigators found no significant association of the fibroid indication for hysterectomy with hypertension or CVD conditions [11].

Several factors have been suggested to explain the association between non-malignant gynecological diseases and hypertension. Common physiological pathways could be involved. It has been found in prospective cohort studies that patients with higher plasma levels of inflammatory response proteins were at higher risk for hypertension [41, 42]. As a result, the chronic systemic inflammation associated with endometriosis may predispose women with this disease to a higher risk of hypertension. Insulin resistance can also be involved as a common pathway between uterine fibroids and hypertension as hyperinsulinemia may elevate fibroid risk by stimulating uterine leiomyomata cell growth $(14,15,23)$. Other mechanisms may also be involved. Hysterectomy is one of the treatments of endometriosis and fibroids. The association between endometriosis or fibroids and hypertension could therefore be mediated by hysterectomy / oophorectomy and earlier age at these surgeries $[13,37,43]$ and greater use of MHT with a longer duration. However, in our study women with a history of endometriosis or fibroids without hysterectomy also had a higher risk of hypertension and analyses were adjusted for hormonal treatment and age at menopause.

\subsection{Strengths and limitations}

Strengths of our study include its prospective design, large sample size, long follow-up with little loss to follow-up and availability of data for most risk factors. Thus, unlike some previous studies, we 
were able to control for body mass index, hormonal treatment, and hysterectomy. Exposure data were collected before diagnosis of hypertension, avoiding potential recall biases. In addition, the prospective design and high rate of follow-up of our study (3.8\% lost to follow-up) minimized the possibility of recall bias or bias due to loss of follow-up. Our study has also limitations. We relied on self-reported diagnosis, and prescription of anti-hypertensive drugs for the identification of hypertension cases. We observed a strong positive predictive value of $82 \%$ for self-reported cases with drug reimbursements, but we could not identify undiagnosed cases. However, these cases should be randomly distributed and would tend to attenuate associations. This cohort is probably not strictly representative of the French population, as educated participants are probably overrepresented. This is usually associated with less hypertension which would consequently tend to attenuate the association. However, incidence of hypertension in our population was similar to the one described in the French population and other countries $[4,5,44]$. As in any observational study, residual confounding may subsist, for example from hypertensive pregnancy disorders, for which data are not available in our study. However, risk of hypertension related to history of hypertensive disorders of pregnancy disorders tend to attenuate with age and is maximal in the first years after pregnancy [45]. As the mean age at inclusion in our population was $50.0 \pm 6.2$ years and the mean age at the diagnosis of hypertension was $59.5+/-7.9$ years, it could be speculated that most women who developed postpregnancy hypertension had prevalent hypertension and were excluded from analysis. Using the Evalues, we found that an unmeasured confounder needs to be associated with both hysterectomy or non-malignant gynecological diseases and hypertension by a risk ratio of roughly 1.5 to explain away the association, which we believe is unlikely as analyses were adjusted for known major risk factors. Misclassification of exposure status is a potential limitation because of the self-reported assessment of surgery, non-malignant gynecological diseases and hypertension. However, when we restricted the analysis to the treated cases, the associations remained consistent. Moreover, a validation study was conducted in the E3N cohort for endometriosis cases [26]. We could not identify undiagnosed cases, that we expect would be randomly distributed and would tend to attenuate associations. Finally, we cannot exclude a potential detection bias where a diagnosis of hypertension would be more likely to 
be made among women with hysterectomy or non-malignant gynecological diseases, because of the medical attention received, as compared with those without the conditions.

\section{Conclusions}

In this large prospective cohort study, women with a history of non-malignant gynecological pathology (hysterectomy, uterine fibroids, or endometriosis) had an increased risk of developing incident hypertension. These findings suggest that women with non-malignant gynecological conditions should be offered surveillance and screening of hypertension for earlier identification and management as hypertension is still underdiagnosed. Increased knowledge and awareness of female specificities in cardiovascular risk is needed to improve women's health as CVD is the major cause of death in women.

\section{Contributors}

Anne-Laure Madika contributed to conceptualization, methodology, formal analysis and investigation, and was responsible for writing the original draft.

Conor James MacDonald contributed to methodology.

Amandine Gelot contributed to methodology, formal analysis and investigation.

Sixtine Hitier contributed to conceptualization.

Claire Mounier-Vehier contributed to conceptualization.

Guillaume Béraud contributed to conceptualization and methodology.

Marina Kvaskoff contributed to conceptualization.

Marie-Christine Boutron-Ruault contributed to conceptualization and was responsible for supervision.

Fabrice Bonnet contributed to conceptualization, methodology, formal analysis and investigation.

All authors contributed to review and editing of the paper. 


\section{Conflict of interest}

The authors declare that they have no conflict of interest.

\section{Funding}

This study was supported the Fédération Française de Cardiologie.

\section{Ethical approval}

All women provided written informed consent and the study was approved by the French National Commission for Data Protection and Individual Freedom, CNIL n 327346 V 13, CPP (03/12/2008).

\section{Provenance and peer review}

This article was not commissioned and was externally peer reviewed.

\section{Research data (data sharing and collaboration)}

There are no linked research data sets for this paper. Data will be made available on request. 


\section{References}

[1] N. Townsend, L. Wilson, P. Bhatnagar, K. Wickramasinghe, M. Rayner, M. Nichols, Cardiovascular disease in Europe: epidemiological update 2016, Eur. Heart J. 37 (2016) 32323245. https://doi.org/10.1093/eurheartj/ehw334.

[2] E. Puymirat, T. Simon, P.G. Steg, F. Schiele, P. Guéret, D. Blanchard, K. Khalife, P. Goldstein, S. Cattan, L. Vaur, J.-P. Cambou, J. Ferrières, N. Danchin, for the USIK USIC 2000 and FAST MI Investigators, Association of Changes in Clinical Characteristics and Management With Improvement in Survival Among Patients With ST-Elevation Myocardial Infarction, JAMA. 308 (2012) 998-1006. https://doi.org/10.1001/2012.jama.11348.

[3] L. Mosca, E.J. Benjamin, K. Berra, J.L. Bezanson, R.J. Dolor, D.M. Lloyd-Jones, L.K. Newby, I.L. Piña, V.L. Roger, L.J. Shaw, D. Zhao, T.M. Beckie, C. Bushnell, J. D'Armiento, P.M. Kris-Etherton, J. Fang, T.G. Ganiats, A.S. Gomes, C.R. Gracia, C.K. Haan, E.A. Jackson, D.R. Judelson, E. Kelepouris, C.J. Lavie, A. Moore, N.A. Nussmeier, E. Ofili, S. Oparil, P. Ouyang, V.W. Pinn, K. Sherif, S.C Jr Smith, G. Sopko, N. Chandra-Strobos, E.M. Urbina, V. Vaccarino, N.K. Wenger, Effectiveness-Based Guidelines for the Prevention of Cardiovascular Disease in Women-2011 Update, Circulation. 123 (2011) 1243-1262. https://doi.org/10.1161/CIR.0b013e31820faaf8.

[4] NCD Risk Factor Collaboration (NCD-RisC), Worldwide trends in blood pressure from 1975 to 2015: a pooled analysis of 1479 population-based measurement studies with $19 \& \# x b 7 ; 1$ million participants, Lancet. 389 (2017) 37-55 https://doi.org/10.1016/S0140-6736(16)319195.

[5] NCD Risk Factor Collaboration (NCD-RisC), Long-term and recent trends in hypertension awareness, treatment, and control in 12 high-income countries: an analysis of 123 nationally representative surveys, Lancet. 394 (2019) 639-651. https://doi.org/10.1016/S01406736(19)31145-6.

[6] R. Cífková, V. Lánská, J. Bruthans, O. jr Mayer, K. Kotseva, D. Wood, D. Lovic, J. De Sutter, Z. Reiner, Z. Fras, J. Deckers, N. Gotcheva, B. Georgiev, D. De Bacquer, on behalf of E.I. V investigators, Blood pressure distribution and control in coronary patients from 24 European countries in the European Society of Cardiology EURoObservational Research Programme European survey of cardiovascular disease prevention and diabetes. EUROASPIRE IV Registry, J.Hypertens. 37 (2019).

https://journals.lww.com/jhypertension/Fulltext/2019/10000/Blood_pressure_distribution_and _control_in.15.aspx.

[7] S. Yusuf, S. Hawken, S. Ôunpuu, T. Dans, A. Avezum, F. Lanas, M. McQueen, A. Budaj, P. Pais, J. Varigos, L. Lisheng, Effect of potentially modifiable risk factors associated with myocardial infarction in 52 countries (the INTERHEART study): case-control study, Lancet. 364 (2004) 937-952. https://doi.org/10.1016/S0140-6736(04)17018-9.

[8] J. Boggia, L. Thijs, T.W. Hansen, Y. Li, M. Kikuya, K. Björklund-Bodegård, T. Richart, T. Ohkubo, J. Jeppesen, C. Torp-Pedersen, E. Dolan, T. Kuznetsova, A. Olszanecka, V. Tikhonoff, S. Malyutina, E. Casiglia, Y. Nikitin, L. Lind, G. Maestre, E. Sandoya, K. Kawecka-Jaszcz, Y. Imai, J. Wang, H. Ibsen, E. O'Brien, J.A. Staessen; International Database on Ambulatory blood pressure in relation to Cardiovascular Outcomes Investigators. Ambulatory Blood Pressure Monitoring in 9357 Subjects From 11 Populations Highlights Missed Opportunities for Cardiovascular Prevention in Women, Hypertension. 57 (2011) 397405. https://doi.org/10.1161/HYPERTENSIONAHA.110.156828.

[9] R. Luoto, J. Kaprio, A. Reunanen, E.-M. Rutanen, Cardiovascular morbidity in relation to 
ovarian function after hysterectomy, Obstet. Gynecol. 85 (1995) 515-522.

https://doi.org/https://doi.org/10.1016/0029-7844(94)00456-N.

[10] K.A. Matthews, C.J. Gibson, S.R. El Khoudary, R.C. Thurston, Changes in cardiovascular risk factors by hysterectomy status with and without oophorectomy: Study of Women's Health Across the Nation, J. Am. Coll. Cardiol. 62 (2013) 191-200.

https://doi.org/10.1016/j.jacc.2013.04.042.

[11] S.K. Laughlin-Tommaso, Z. Khan, A.L. Weaver, C.D. Schleck, W.A. Rocca, E.A. Stewart, Cardiovascular risk factors and diseases in women undergoing hysterectomy with ovarian conservation, Menopause. 23 (2016) 121-128. https://doi.org/10.1097/GME.0000000000000506.

[12] D.-C. Ding, I.-J. Tsai, C.Y. Hsu, J.-H. Wang, S.-Z. Lin, F.-C. Sung, Risk of hypertension after hysterectomy: a population-based study, BJOG An Int. J. Obstet. Gynaecol. 125 (2018) 17171724. https://doi.org/https://doi.org/10.1111/1471-0528.15389.

[13] M. Fan, R.-E. Janet, R.E. B., S. Donna, F.J. P., M.S. A., Association Between Endometriosis and Hypercholesterolemia or Hypertension, Hypertension. 70 (2017) 59-65.

https://doi.org/10.1161/HYPERTENSIONAHA.117.09056.

[14] Y.C. Haan, I. Oudman, M.E. de Lange, A. Timmermans, W.M. Ankum, G.A. van Montfrans, L.M. Brewster, Hypertension Risk in Dutch Women With Symptomatic Uterine Fibroids, Am. J. Hypertens. 28 (2015) 487-492. https://doi.org/10.1093/ajh/hpu183.

[15] Y.C. Haan, F.S. Diemer, L. Van Der Woude, G.A. Van Montfrans, G.P. Oehlers, L.M. Brewste, The risk of hypertension and cardiovascular disease in women with uterine fibroids, J. Clin. Hypertens. (Greenwich). 20 (2018) 718-726. doi: 10.1111/jch.13253. Epub 2018 Mar 22. PMID: 29569360.

[16] A. Hammer, A.F. Rositch, J. Kahlert, P.E. Gravitt, J. Blaakaer, M. Søgaard, Global epidemiology of hysterectomy: possible impact on gynecological cancer rates, Am. J. Obstet. Gynecol. 213 (2015) 23-29. https://doi.org/10.1016/j.ajog.2015.02.019.

[17] J.D. Wright, T.J. Herzog, J. Tsui, C. V Ananth, S.N. Lewin, Y.-S. Lu, A.I. Neugut, D.L. Hershman, Nationwide trends in the performance of inpatient hysterectomy in the United States, Obstet. Gynecol. 122 (2013) 233-241. https://doi.org/10.1097/AOG.0b013e318299a6cf.

[18] R.K. Menon, F.E. Okonofua, J.E. Agnew, M. Thomas, J. Bell, P.M.S. O’Brien, P. Dandona, Endocrine and metabolic effects of simple hysterectomy, Int. J. Gynecol. Obstet. 25 (1987) 459-463. https://doi.org/https://doi.org/10.1016/0020-7292(87)90062-2.

[19] C.M. Farquhar, L. Sadler, S.A. Harvey, A.W. Stewart, The association of hysterectomy and menopause: a prospective cohort study, BJOG An Int. J. Obstet. Gynaecol. 112 (2005) 956962. https://doi.org/https://doi.org/10.1111/j.1471-0528.2005.00696.x.

[20] M.A. Silver, R. Raghuvir, B. Fedirko, D. Elser? Systemic hypertension among women with uterine leiomyomata: potential final common pathways of target end-organ remodeling, J. Clin. Hypertens. (Greenwich). 7 (2005) 664-8. doi: 10.1111/j.1524-6175.2005.04384.x. PMID: 16278524.

[21] N.S. Moss, E.P. Benditt, Human atherosclerotic plaque cells and leiomyoma cells. Comparison of in vitro growth characteristics, Am. J. Pathol. 78 (1975) 175-190.

https://pubmed.ncbi.nlm.nih.gov/163592.

[22] M. Malik, J. Norian, D. McCarthy-Keith, J. Britten, W.H. Catherino, Why leiomyomas are called fibroids: the central role of extracellular matrix in symptomatic women, Semin. Reprod. Med. 28 (2010) 169-79. doi: 10.1055/s-0030-1251475. Epub 2010 Apr 22. PMID: 20414841. 
[23] N. Sivri, T. Yalta, C. Sayın, K. Yalta, F. Ozpuyan, E. Taştekin, E. Yetkin, Evaluation of cardiovascular risk factors in women with uterine leimyoma: is there a link with atherosclerosis?, Balkan Med. J. 29 (2012) 320-323.

https://doi.org/10.5152/balkanmedj.2012.002.

[24] F. Clavel-Chapelon, for the E.S. Group, Cohort Profile: The French E3N Cohort Study, Int. J. Epidemiol. 44 (2015) 801-809. https://doi.org/10.1093/ije/dyu184.

[25] M. Kvaskoff, A. Bijon, F. Clavel-Chapelon, S. Mesrine, M.-C. Boutron-Ruault, Childhood and Adolescent Exposures and the Risk of Endometriosis, Epidemiology. 24 (2013).

https://journals.lww.com/epidem/Fulltext/2013/03000/Childhood_and_Adolescent_Exposures _and_the_Risk_of.14.aspx.

[26] M. Lajous, L. Tondeur, G. Fagherazzi, B. de Lauzon-Guillain, M.-C. Boutron-Ruaualt, F. Clavel-Chapelon, Processed and Unprocessed Red Meat Consumption and Incident Type 2 Diabetes Among French Women, Diabetes Care. 35 (2012) 128 LP - 130. https://doi.org/10.2337/dc11-1518.

[27] B. Tehard, M.J.Van Liere, C.C. Nougué, F. Clavel-Chapelon, Anthropometric Measurements and Body Silhouette of Women: Validity and Perception, J. Am. Diet. Assoc. 102 (2002) 1779-1784. https://doi.org/10.1016/S0002-8223(02)90381-0.

[28] M.J. van Liere, F. Lucas, F. Clavel, N. Slimani, S. Villeminot, Relative validity and reproducibility of a French dietary history questionnaire., Int. J. Epidemiol. 26 (1997) S128S128. https://doi.org/10.1093/ije/26.suppl_1.S128.

[29] F. Clavel-Chapelon, N. Dormoy-Mortier, A validation study on status and age of natural menopause reported in the E3N cohort, Maturitas. 29 (1998) 99-103. https://doi.org/10.1016/S0378-5122(98)00020-6.

[30] T.J.VanderWeele, P. Ding, Sensitivity Analysis in Observational Research: Introducing the EValue. Ann Intern Med. 167 (2017) 268-274. https://doi.org/10.7326/M16-2607.

[31] S.K. Laughlin-Tommaso, Z. Khan, A.L. Weaver, C.Y. Smith, W.A. Rocca, E.A. Stewart, Cardiovascular and metabolic morbidity after hysterectomy with ovarian conservation: a cohort study, Menopause. 25 (2018).

https://journals.lww.com/menopausejournal/Fulltext/2018/05000/Cardiovascular_and_metabol ic_morbidity_after.6.aspx.

[32] B.V. Howard, L. Kuller, R. Langer, J.E. Manson, C. Allen, A. Assaf, B.B. Cochrane, J.C. Larson, N. Lasser, M. Rainford, L. Van Horn, M.L. Stefanick, M. Trevisan; Women's Health Initiative, Risk of Cardiovascular Disease by Hysterectomy Status, With and Without Oophorectomy, Circulation. 111 (2005) 1462-1470. https://doi.org/10.1161/01.CIR.0000159344.21672.FD.

[33] C.J. Gibson, R.C. Thurston, S.R. El Khoudary, K. Sutton-Tyrrell, K.A. Matthews, Body mass index following natural menopause and hysterectomy with and without bilateral oophorectomy, Int. J. Obes. (Lond). 37 (2013) 809-813. https://doi.org/10.1038/ijo.2012.164.

[34] E. Ingelsson, C. Lundholm, A.L. V Johansson, D. Altman, Hysterectomy and risk of cardiovascular disease: a population-based cohort study, Eur. Heart J. 32 (2011) 745-750. https://doi.org/10.1093/eurheartj/ehq477.

[35] C.M. Rivera, B.R. Grossardt, D.J. Rhodes, R.D.J. Brown, V.L. Roger, L.J.I.I.I. Melton, W.A. Rocca, Increased cardiovascular mortality after early bilateral oophorectomy, Menopause. 16 (2009).

https://journals.lww.com/menopausejournal/Fulltext/2009/16010/Increased_cardiovascular_m ortality_after_early.7.aspx. 
[36] F. Atsma, M.-L.E.L. Bartelink, D.E. Grobbee, Y.T. van der Schouw, Postmenopausal status and early menopause as independent risk factors for cardiovascular disease: a meta-analysis, Menopause. 13 (2006).

https://journals.lww.com/menopausejournal/Fulltext/2006/13020/Postmenopausal_status_and_ early_menopause_as.17.aspx.

[37] W.H. Parker, D. Feskanich, M.S. Broder, E. Chang, D. Shoupe, C.M. Farquhar, J.S. Berek, J.E. Manson, Long-term mortality associated with oophorectomy compared with ovarian conservation in the nurses' health study, Obstet. Gynecol. 121 (2013) 709-716. https://doi.org/10.1097/AOG.0b013e3182864350.

[38] Anagnostis P, Theocharis P, Lallas K, Konstantis G, Mastrogiannis K, Bosdou JK, Lambrinoudaki I, Stevenson JC, Goulis DG. Early menopause is associated with increased risk of arterial hypertension: A systematic review and meta-analysis, Maturitas. 135 (2020) 74-79. doi: 10.1016/j.maturitas.2020.03.006.

[39] F. Mu, J. Rich-Edwards, E.B. Rimm, D. Spiegelman, S.A. Missmer, Endometriosis and Risk of Coronary Heart Disease, Circ. Cardiovasc. Qual. Outcomes. 9 (2016) 257-264. https://doi.org/10.1161/CIRCOUTCOMES.115.002224.

[40] S.K. Laughlin-Tommaso, E.L. Fuchs, M.F. Wellons, C.E. Lewis, R. Calderon-Margalit, E.A. Stewart, P.J. Schreiner, Uterine Fibroids and the Risk of Cardiovascular Disease in the Coronary Artery Risk Development in Young Adult Women's Study, J. Women's Heal. 28 (2018) 46-52. https://doi.org/10.1089/jwh.2018.7122

[41] G. Engström, P. Lind, B. Hedblad, L. Stavenow, L. Janzon, F. Lindgärde, Long-Term Effects of Inflammation-Sensitive Plasma Proteins and Systolic Blood Pressure on Incidence of Stroke, Stroke. 33 (2002) 2744-2749. https://doi.org/10.1161/01.STR.0000034787.02925.1F.

[42] H.D. Sesso, L. Wang, J.E. Buring, P.M. Ridker, J.M. Gaziano, Comparison of Interleukin-6 and C-Reactive Protein for the Risk of Developing Hypertension in Women, Hypertension. 49 (2007) 304-310. https://doi.org/10.1161/01.HYP.0000252664.24294.ff.

[43] M. Kvaskoff, F. Mu, K.L. Terry, H.R. Harris, E.M. Poole, L. Farland, S.A. Missmer, Endometriosis: a high-risk population for major chronic diseases?, Hum. Reprod. Update. 21 (2015) 500-516. https://doi.org/10.1093/humupd/dmv013.

[44] A.L. Perrine, C. Lecoffre, J. Blacher, V. Olié, L’hypertension artérielle en France : prévalence, traitement et contrôle en 2015 et évolutions depuis 2006. Bull Epidémiol Hebd, 10 (2018) 170-9. http://invs.santepubliquefrance.fr/beh/2018/10/2018_10_1.html

[45] I. Behrens, S. Basit, M. Melbye, J.A. Lykke, J. Wohlfahrt, H. Bundgaard, B. Thilaganathan, H.A. Boyd,

Risk of post-pregnancy hypertension in women with a history of hypertensive disorders of pregnancy: nationwide cohort study, BMJ. 358 (2017) j3078.

https://doi.org/10.1136/bmj.j3078. 
Table 1. Baseline participant characteristics according to hysterectomy status $(n=50$ 286).

\section{Covariates: $n(\%)$ or mean \pm SD}

Age at inclusion (years)

Smoking status

Never

Past

Current

History of diabetes

Body mass index $\left(\mathrm{kg} / \mathrm{m}^{2}\right)$

Physical activity (METs-h/w)

Family history of hypertension

Level of education

No High school

High school

University

Age at menarche (years)

$$
\begin{aligned}
& <13 \\
& \geq 13
\end{aligned}
$$

20098 (44.4)

25146 (55.6)

23197 (51.3)

6819 (15.1)

15228 (33.7)

$226(0.5)$

$22.2 \pm 2.8$

$44.2 \pm 27.4$

$12170(26.9)$

4717 (10.4)

$22802(50.4)$

17725 (39.2)

Hysterectomy

$(n=5042)$

$$
53.1 \pm 6.2
$$

2838 (56.3)

624 (12.4)

1580 (31.3)

$37(0.7)$

$22.8 \pm 3.0$

$46.1 \pm 29.2$

$1326(26.3)$

830 (16.5)

2713 (53.8)

1499 (29.7)

2438 (48.4)

2604 (51.6)

Use of oral contraceptives

Never

15109 (33.4)

2701 (53.6)

Ever

30135 (66.6)

2341 (46.4)

Use of intrauterine device

Never

24033 (53.1)

3641 (72.2)

Ever

21211 (46.9)

1401 (27.8)

Number of pregnancies

0

1- 2

3-4

$\geq 5$

Menopausal status and age at menopause

Premenopausal

Postmenopausal before 45 years

Postmenopausal between 45 and 52 years
$28180(62.3)$

3994 (8.8)

20713 (45.8)

16874 (37.3)

$3663(8.1)$

$1317(2.9)$

$12508(27.6)$
1334 (26.5)

$1010(20.0)$

594 (11.8)

2256 (44.7)

1759 (34.9)

$433(8.6)$

$2375(47.1)$ 


\section{No hysterectomy Hysterectomy}

Covariates: $\mathbf{n}(\%)$ or mean $\mathbf{\pm S D}$

$(n=45244) \quad(n=5042)$

Postmenopausal after 52 years

$3239(7.2)$

$323(6.4)$

Use of menopausal hormone therapy

Never

$37246(82.3)$

$3062(60.7)$

Ever

$1980(39.3)$ 
Table 2. Hazard ratios (HRs) and $95 \%$ confidence intervals (95\% CIs) for incident hypertension according to medical history of hysterectomy.

M1

\begin{tabular}{|c|c|c|c|c|c|c|c|c|}
\hline $\begin{array}{c}\text { Number } \\
\text { of non- } \\
\text { cases }\end{array}$ & $\begin{array}{c}\text { Number } \\
\text { of cases } \\
(\%)\end{array}$ & $\begin{array}{r}\text { Person- } \\
\text { years }\end{array}$ & $\begin{array}{c}\text { HR } \\
{[95 \% \mathrm{CI}]}\end{array}$ & p-value & $\begin{array}{c}\text { HR }[95 \% \\
\text { CI] }\end{array}$ & p-value & $\begin{array}{c}\text { HR } \\
{[95 \% \mathrm{CI}]}\end{array}$ & p-value \\
\hline
\end{tabular}

M3

M2

\section{Hysterectomy}

(HT)

Never

Ever

\section{Surgical}

intervention*

No

intervention

HT alone

HT and

oophorectomy

Oophorectomy alone

Age at HT (years)

\section{No HT}

$<40$

[40-50]

$\begin{array}{rrrr}31828 & 9947575398 & \\ (83.3) & (82.4) & \text { Reference } & \\ & & & \\ 6385 & 2126 & 94549 & \mathbf{1 . 1 9} \\ (16.7) & (17.6) & & {[\mathbf{1 . 1 3} ;<0.0001} \\ & & & \mathbf{1 . 2 4}]\end{array}$

Reference

Reference

1.12

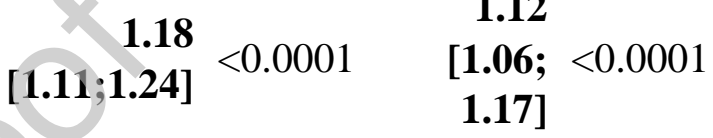

\section{(1)} 更 


\begin{tabular}{|c|c|c|c|c|c|c|c|c|}
\hline $\begin{array}{c}\text { Number } \\
\text { of non- } \\
\text { cases } \\
(\%)\end{array}$ & $\begin{array}{c}\text { Number } \\
\text { of cases } \\
(\%)\end{array}$ & $\begin{array}{r}\text { Person- } \\
\text { years }\end{array}$ & $\begin{array}{c}\text { HR } \\
{[95 \% \mathrm{CI}]}\end{array}$ & p-value & $\begin{array}{c}\text { HR }[95 \% \\
\text { CI }]\end{array}$ & p-value & $\begin{array}{c}\text { HR } \\
{[95 \% \mathrm{CI}]}\end{array}$ & p-value \\
\hline \multirow[t]{2}{*}{$\begin{array}{l}2368 \\
(6.2)\end{array}$} & $\begin{array}{r}580 \\
(4.8)\end{array}$ & 7568 & $\begin{array}{r}1.12 \\
{[1.03 ;} \\
1.22]\end{array}$ & 0.0061 & $\begin{array}{r}1.12[1.03 ; \\
1.22]\end{array}$ & 0.0067 & $\begin{array}{r}1.09 \\
{[1.00 ;} \\
1.19]\end{array}$ & 0.0472 \\
\hline & & & & $<0.0001$ & & $<0.0001$ & & $<0.0001$ \\
\hline
\end{tabular}

BMI: Body mass index, HT= hysterectomy

*Missing data on age of oophorectomy in 157 women (0.003\%), ending up with 50129 women for analysis M1: Model adjusted for age (timescale)

M2: M1 further adjusted for smoking status (nonsmoker, former smoker, or current smoker; time dependent), level of recreational physical activity (metabolic equivalent task-hours per week, as tertiles), history of diabetes (nolyes, time dependent), family history of hypertension (yes/no), education level (no high school, high school, university), age at menarche ( $<13$ years $\$ 13$ years), menopausal status and age at menopause (no menopause/menopause before 45 years/menopause between 45 and 52 years/menopause after 52 years, time dependent), menopausal hormone therapy use (ever/never; time dependent), use of oral contraceptives (ever/never; time dependent), use of intrauterine device (ever/never), and number of pregnancies (0/1 or 2/3 or $\geq 4$ pregnancies).

M3: M2 further adjusted for BMI (continuous, time dependent) 
Table 3. Hazard ratios (HRs) and $95 \%$ confidence intervals (95\% CIs) for incident hypertension according to non-malignant gynecological diseases.

M1 M2 M3

\begin{tabular}{|c|c|c|c|c|c|c|c|}
\hline $\begin{array}{c}\text { Number } \\
\text { of non- } \\
\text { cases }\end{array}$ & $\begin{array}{c}\text { Number } \\
\text { of cases } \\
(\%)\end{array}$ & $\begin{array}{c}\text { HR } \\
{[95 \% \mathrm{CI}]}\end{array}$ & p-value & $\begin{array}{c}\text { HR } \\
{[95 \% \mathrm{CI}]}\end{array}$ & p-value & $\begin{array}{c}\text { HR } \\
{[95 \% \mathrm{CI}]}\end{array}$ & p-value \\
\hline
\end{tabular}

History of

endometriosis

Never

$\begin{array}{lll}35496 & 11209 \\ (92.9) & (92.8) & \text { Reference }\end{array}$

1.20

$2717 \quad 864$

(7.1)

(7.2)

[1.12;<0.0001

1.29]

1.21

$2444 \quad 793$

(6.4)

(6.6)

[1.13; <0.0001

1.30]

1.21

[1.11; <0,0001

1.31]

(5.2) (5.3)

confirmed

625
$5.3)$

Reference

Reference

$1.19 \quad 1.14$

[1.11; <0.0001

1.22]

[1.07;<0.0001

1.23]

$1.19 \quad 1.15$

[1.11; <0.0001

1.29]

$[1.07 ;<0.0001$

1.23]

$1.19 \quad 1.14$

$[1.10 ;<0.0001$

1.29]

History of

fibroids

Never

$\begin{array}{ll}26963 & 8454 \\ (70.2) & (70.0)\end{array}$ Reference

Reference

Reference

Self-

$11250 \quad 3616$

1.18

1.18

1.13

reported

(29.4) (30.0)

[1.14; <0.0001

1.23]

[1.13;<0.0001

1.22]

[1.08; <0.0001

1.17]

Medically

$9446 \quad 3158$

(25.9)

(27.2)

1.19

1.19

1.13

confirmed

[1.15; <0.0001

1.24]

[1.14; <0.0001

1.24]

[1.09; <0.0001

1.18]

1.21

1.15

Surgically

$6580 \quad 2231$

confirmed

(19.6)

(20.9)

1.22

[1.15; <0.0001

1.25]

[1.09; <0.0001

1.28]

1.20] 


\begin{tabular}{|c|c|c|c|c|c|c|c|}
\hline $\begin{array}{c}\text { Number } \\
\text { of non- } \\
\text { cases } \\
(\%)\end{array}$ & $\begin{array}{c}\text { Number } \\
\text { of cases } \\
(\%)\end{array}$ & $\begin{array}{c}\text { HR } \\
{[95 \% \mathrm{CI}]}\end{array}$ & p-value & $\begin{array}{c}\text { HR } \\
{[95 \% \mathrm{CI}]}\end{array}$ & p-value & $\begin{array}{c}\text { HR } \\
{[95 \% \mathrm{CI}]}\end{array}$ & p-value \\
\hline
\end{tabular}

BMI: Body mass index, $H T=$ hysterectomy

M1: Model adjusted for age (timescale)

M2: M1 further adjusted for smoking status (nonsmoker, former smoker, or current smoker; time dependent), level of recreational physical activity (metabolic equivalent task-hours per week, as tertiles), history of diabetes (no/yes, time dependant), family history of hypertension (yes/no), education level (no high school, high school, university), age at menarche ( $<13$ years $>13$ years), menopausal status and age at menopause (no menopause/menopause before 45 years/menopause between 45 and 52 years/menopause after 52 years, time dependent), menopausal hormone therapy use (ever/never; time dependent), use of oral contraceptives (ever/never; time dependent), use of intrauterine device (ever/never), and number of pregnancies ( $0 / 1$ or $2 / 3$ or $\geq 4$ pregnancies).

M3: M2 further adjusted for BMI (continuous, time dependent) 
Table 4. Hazard ratios (HRs) and $95 \%$ confidence intervals (95\% CIs) for incident hypertension according to non-malignant gynecological diseases and history of hysterectomy.

\section{M1}

M2

M3

\begin{tabular}{|c|c|c|c|c|c|c|c|}
\hline $\begin{array}{c}\text { Number } \\
\text { of non- } \\
\text { cases } \\
(\%)\end{array}$ & $\begin{array}{c}\text { Number } \\
\text { of } \\
\text { cases } \\
(\%)\end{array}$ & $\begin{array}{c}\text { HR } \\
{[95 \%} \\
\text { CI] }\end{array}$ & $\begin{array}{c}\text { p- } \\
\text { value }\end{array}$ & $\begin{array}{c}\text { HR } \\
{[95 \%} \\
\text { CI] }\end{array}$ & $\begin{array}{c}\text { p- } \\
\text { value }\end{array}$ & $\begin{array}{c}\text { HR } \\
{[95 \%} \\
\text { CI }]\end{array}$ & $\begin{array}{c}\text { p- } \\
\text { value }\end{array}$ \\
\hline
\end{tabular}

HT and endometriosis

history*

No HT and no

endometriosis

$\begin{array}{lr}30130 & 9430 \\ (78.9) & (78.1)\end{array}$ Reference

Reference

Reference

HT without

endometriosis

$\begin{array}{rrr}5366 & 1779 & \mathbf{1 . 1 8} \\ (14.0) & (14.7) & {[\mathbf{1 . 1 2} ;<0.0001} \\ & & \mathbf{1 . 2 4}]\end{array}$

1.18

1.12

[1.12; <0.0001

[1.07; <0.0001

1.24]

1.18]

Endometriosis

1698

1.20

1.19

1.17

without HT

(4.4)

517
$(4.3)$

[1.09; <0.0001

[1.09; 0.0001

1.31]

1.30]

[1.07; 0.0007

$1.29 \quad 1.27$

1.27]

Endometriosis

1019

(2.7)

347

[1.16;<0.0001

[1.14; <0.0001

1.24

with $\mathrm{HT}$

(2.9)

1.43]

[1.11; 0.0001

1.42]

1.38]

HT and

fibroids

history*

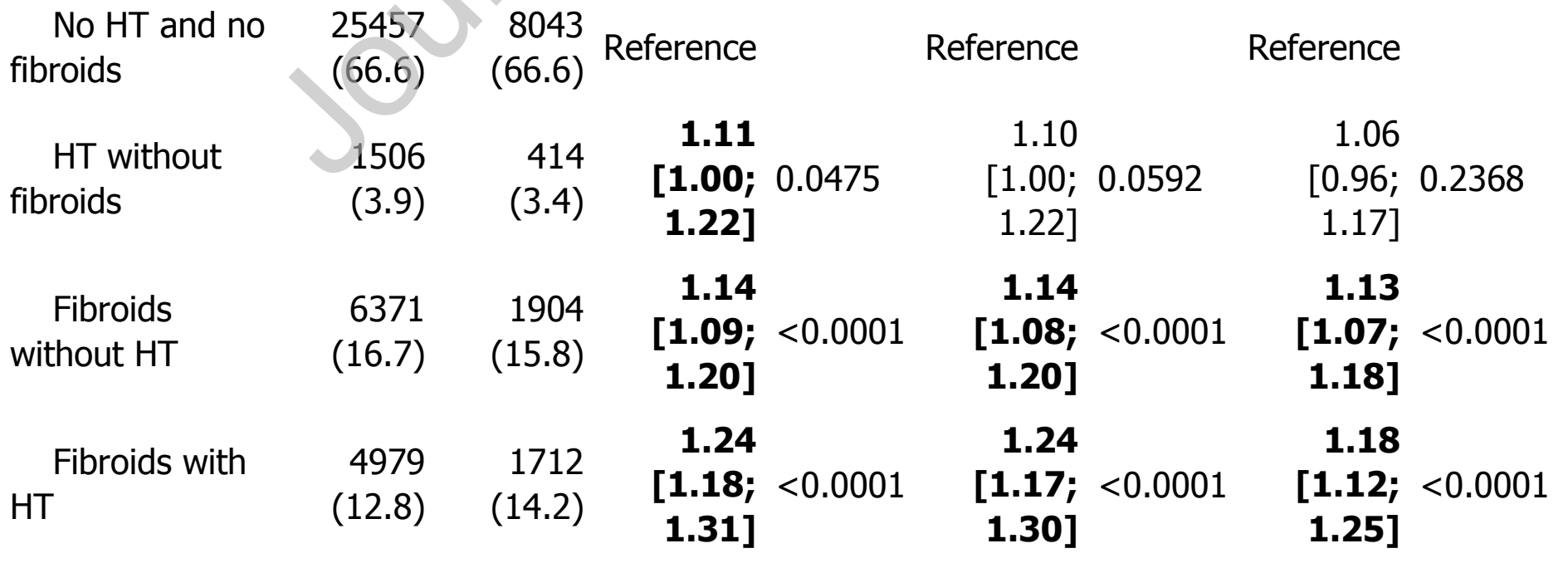




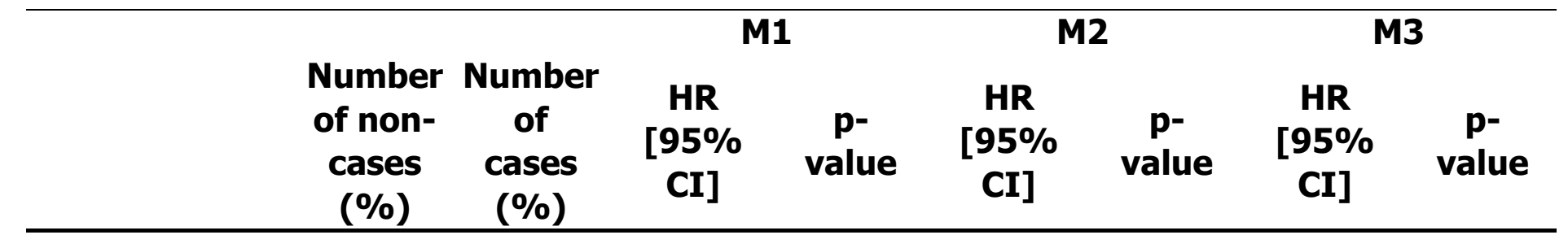

*Endometriosis and fibroids history were self-reported

BMI: Body mass index, HT= hysterectomy

M1: Model adjusted for age (timescale)

M2: M1 further adjusted for smoking status (nonsmoker, former smoker, or current smoker; time dependent), level of recreational physical activity (metabolic equivalent task-hours per week, as tertiles), history of diabetes (no/yes, time dependant), family history of hypertension (yes/no), education level (no high school, high school, university), age at menarche ( $<13$ years/ $\geq 13$ years), menopausal status and age at menopause (no menopause/menopause before 45 years/menopause between 45 and 52 years/menopause after 52 years, time dependent), menopausal hormone therapy use (ever/never; time dependent), use of oral contraceptives (ever/never; time dependent), use of intrauterine device (ever/never), and number of pregnancies ( 0 / 1 or $2 / 3$ or $\geq 4$ pregnancies).

M3: M2 further adjusted for BMI (continuous, time dependent) 